strains of Bordetella pertussis." One of the liquidmedium vaccines (coded V15) was made at the Lister Institute; the other liquid-medium vaccine was coded V14 and the solid-medium vaccine V12. In this field trial the Lister vaccine, V15, performed consistently better than V14, V12 being intermediate in efficacy. In laboratory tests V 15 was significantly more potent than both V14 and V12. But having made this point I should not think of using it to suggest that any one method of manufacture is "better" than any other; another trial with different batches of vaccine would possibly give somewhat different results.

(4) Telephone calls to these laboratories following the appearance of Dr Griffith's paper and your leading article indicate that the impression has been created among some that pertussis vaccines other than Wellcome's may be less potent or more toxic. Practitioners should be aware that all such vaccines made in Britain have to meet identical statutory specifications and that no batch of vaccine containing an adsorbed pertussis component may be distributed until a sample has been submitted to the National Institute of Biological Standards and Control for examination before release.

(5) On the question of toxicity, the Wellcome method of growing vaccine on medium containing charcoal may indeed absorb out "bacterial toxins" (p 811); but the association of these putative toxins with adverse reactions in children is, as I am sure Dr Griffith would agree, a very moot point. In this connection-and in any consideration of reactions to pertussis vaccine-it is important to be clear as to what is meant by "toxicity." $B$ pertussis can induce a remarkable range of responses in small animals some of them appear to be associated with specific components of the organism, but none has as yet been unequivocally linked with reactions in children, which fall into two main groups: first, the sort of local inflammatory response, with or without transient fever and malaise, that can be caused by any bacterial vaccine, including the diphtheria and tetanus toxoids contained in the triple preparation; and second, the more serious reactions such as collapse, persistent screaming, convulsions, and encephalopathy. There is evidence ${ }^{3}$ that toxicity tests in animals are of some use in predicting the liability of a given batch of vaccine to induce reactions in the first category; but-for the moment begging the question of a cause-and-effect relationship between pertussis vaccine and central nervous system (CNS) reactions-there is at present simply no evidence that the reactions in the second category are determined by the strains of $B$ pertussis used, method of manufacture, or performance in any laboratory test. The comparative rarity of these serious reactions bedevils any attempt to relate them to such variables in pertussis vaccine-if indeed such a relationship exists; in addition to the possibility, referred to by Dr Griffith, that some reactions may be purely coincidental, susceptibility to convulsions or other CNS complications could be determined by factors pertaining to a particular child rather than to a particular vaccine. Again, such reactions might not be specific to pertussis; were it customary to inject large numbers of infants with vaccines made from other Gram-negative organisms such as cholera or typhoid, might not similar accidents occur from time to time ?4

I share Dr Griffith's concern about the difficulty of obtaining reports of untoward reactions and about the poor quality of some of the information that is received. In view of the low incidence of major adverse reactions to pertussis vaccine every case is potentially valuable as a source of information and should be adequately recorded by a central agency; and means should be found of making such records available to manufacturers. For their part, manufacturers should obtain and record as much information as is practicable about the vaccines they distribute. It is the collation of the data from the field with those from the laboratory that provides the major challenge; this is an outstanding example of a problem in which the ability to pose the right questions at the outset will determine the validity of the answers.

\section{H COLLIER}

Vaccines and Sera Laboratories

Lister Institute of Preventive Medicine,

Elstree, Herts

Public Health Laboratory Service Whooping Cough Committee and Working Party, British Medical

Report of the MRC Whooping-Cough Committee, Prins, F T, et al, Sympl, 1959, 1, 994.

Standardizet al, Symposia Series in Immunobiological Camerdardization, $1970,13,141$. 20, 57 .

\section{"Human Growth and its Disorders"}

SIR,-May I draw your readers' attention to an unfortunate error in my book "Human Growth and its Disorders" published by Academic Press? On p 166 the text states that testosterone oenanthate should be given intravenously. It should, of course, be given intramuscularly. Intravenous injection would be highly dangerous.

Sales of the book have been discontinued pending the insertion of errata and every effort is being made to contact those who have already purchased copies. I should be grateful if any readers who possess copies of the book but have not received correction slips would contact me.

My thanks are due to Dr A Stuart Mason for mentioning this error in your review columns (1 April, p 845).

\section{W A Marshall}

Department of Human Sciences

University of Technology, Loughborough, Leics

\section{Beta-blockers and plasma triglycerides}

SIR,-We have been conducting a trial comparing the effects of propranolol (160$240 \mathrm{mg}$ ), pindolol (15-30 $\mathrm{mg})$, and atenolol $(100 \mathrm{mg})$ given as a single daily dose for the control of hypertension. A randomised block design was used so that each patient received all of the treatments. We observed small but significant increases in fasting plasma triglyceride levels after four weeks of treatment with these drugs when compared with the placebo phases. These rises were not accompanied by changes in plasma cholesterol or blood glucose levels. Although the rise was greatest with atenolol, the changes were significant with all three drugs (see table). Subsequently we examined the effects of metoprolol in the same group of 17 patients. After a further period on placebo patients were given metoprolol $100 \mathrm{mg}$ daily. Again a small but significant rise in fasting plasma triglyceride levels was observed.

While food and alcohol intake may well account for major fluctuations in triglyceride levels, the evidence from plasma glucose and insulin determinations, particularly in the latter experiment, indicates that all of the subjects were fasting at the time of blood sampling. From direct questioning and our knowledge of the patients only three are regular heavy alcohol users and the fluctuations in their plasma triglyceride levels observed during these studies did not correlate with periods of heavy alcohol intake.

Previous authors ${ }^{1: 3}$ have reported varying changes in plasma triglyceride levels in patients taking $\beta$-adrenoceptor antagonists. Most have reported the effect of a single drug and have not compared the effects of different drugs within a group of patients.

In view of the associations between hypertension, coronary artery disease, and blood lipids these findings may have important implications. If plasma triglyceride levels remain elevated during long-term treatment of hypertension with $\beta$-adrenoceptor antagonists, do the benefits outweigh the risks?

J SHaW

J D F ENGLAND A S P HuA

University Department of Medicine,

Royal Melbourne Hospital, Melbourne, Victoria

Barboriak, J P, and Friedberg, H D, Atherosclerosis, $1973,17,31$

Nilsson, A, Hansson, B-G, and Hökfelt, D, British Medical fournal, 1977, 2, 126

Waal-Manning, H J, Drugs, 1976, 11, suppl 1, p 121

\section{Price of survival in childhood leukaemia}

SIR,-Your leading article (11 February, p 321) emphasises the need for long-term surveillance of children who have completed two or three years of intensive therapy for lymphoblastic leukaemia. This is already standard practice in children who appear to have been cured of solid tumours and there is now substantial evidence for clinically significant growth hormone deficiency in children who have received high-dose (5000-6000 R) irradiation for the treatment of intracranial tumours.' These children, however, have often had the associated problems of raised intracranial pressure and neurosurgical intervention.

The effects of leukaemia therapy on growth and the endocrine system is not so clear-cut and the results you quote from the Manchester group of Shalet et al have not as yet been substantiated by other centres. Shalet et al have described a blunted growth hormone response to hypoglycaemia rather than growth hormone deficiency except in one girl who received more than the now conventional doses of radiation. The quoted cortisol responses $^{3}$ (not corticotrophin (ACTH) as suggested in your article) to hypoglycaemia are all within the normal limits and the

Mean fasting plasma triglyceride, plasma cholesterol, and blood glucose concentrations $( \pm S E M)$ and fasting insulin levels in 17 patients during treatment with placebo and beta-blockers

\begin{tabular}{|c|c|c|c|c|c|}
\hline & Placebo & Atenolol & Pindolol & Propranolol & Metoprolol \\
\hline $\begin{array}{l}\text { Triglycerides } \\
(\text { mmol } 1)\end{array}$ & $1 \cdot 35 \div 0 \cdot 11$ & $2 \cdot 19 \dashv 0 \cdot 44^{*}$ & $1 \cdot 73 \pm 0 \cdot 19^{*}$ & $1 \cdot 85+0 \cdot 28^{*}$ & $1.79: 0.22^{*}$ \\
\hline $\begin{array}{l}\text { (mmol/1) } \\
\text { Glucose (mmol/1) } \\
\text { Insulin }(\mathrm{mU} / \mathrm{l})\end{array}$ & $\begin{array}{c}5 \cdot 5: 0 \cdot 21 \\
4 \cdot 3: 0 \cdot 21 \\
12 \cdot 2\end{array}$ & $\begin{array}{c}5 \cdot 6+0 \cdot 33 \\
4 \cdot 1+0 \cdot 16 \\
12 \cdot 5\end{array}$ & $\begin{array}{c}5 \cdot 8+0 \cdot 28 \\
4 \cdot 0-0 \cdot 11 \\
11 \cdot 8\end{array}$ & $\begin{array}{c}5 \cdot 7 \pm 0 \cdot 27 \\
4 \cdot 1=0 \cdot 15 \\
12 \cdot 5\end{array}$ & $\begin{array}{c}5 \cdot 6: 0 \cdot 22 \\
4 \cdot 1 \div 0 \cdot 15 \\
13 \cdot 3\end{array}$ \\
\hline
\end{tabular}

P $<0.05$ bv paired $t$ test
Conversion: SI to traditional units-Triglycerides: $1 \mathrm{mmol} / 1 \approx 88 \mathrm{mg} / 100 \mathrm{ml}$. Cholesterol: $1 \mathrm{mmol} / 1 \approx 39 \mathrm{mg} / 100 \mathrm{ml}$. Glucose: $1 \mathrm{mmol} / 1 \approx 18 \mathrm{mg} / 100 \mathrm{ml}$. 
thyrotrophin ( $\mathrm{TSH}$ ) responses in three cases are reminiscent of primary hypothyroidism rather than hypothalamic disease.

We have evaluated the growth and hormonal status of 14 children now aged 7-15 years who have been off leukaemia treatment for at least $1 \cdot 1$ years. In the year after stopping chemotherapy these children had a mean growth rate of $8 \mathrm{~cm} /$ year (range $4.9-11.2 \mathrm{~cm} /$ year) and their linear growth has been maintained in all cases. We have not found any significant hormonal disturbance in those children who agreed to undergo a combined hypothalamic-anterior pituitary function test, and the older children are passing normally through puberty.

We agree that long-term careful surveillance of these children is mandatory but suggest that endocrine investigation is necessary only when their growth or development gives cause for concern.

Peter SWift

D C L SAVAGE M G MOTT

J A Bullimore

Royal.Hospital for Sick Children,

Bristol

Richards, G E, et al, fournal of Pediatrics, 1976, 89, 553.

Shalet, S M, et al, Archives of Disease in Childhood, 1976, 51, 489 .

${ }^{3}$ Shalet, S M, et al, fournal of Pediutrics, 1977, 70, 920.

\section{Transmission of agent of}

\section{Creutzfeldt-Jakob disease}

SIR,-Your leading article "Creutzfeldt-Jakob under control" (25 February, p 463), raising the question of transmission of the spongiform encephalopathies and in particular the risk factors associated with medical and surgical techniques, prescribes "a close watch on all human-to-human transfers of material by artificial means." We have recently studied the possibility of such transmission by dental procedures, which may carry the risk of transfer between patients (or between patient and dentist) of gingival tissue contaminating dental burrs. Scrapie infection in mice reproduces many of the clinical features of Creutzfeldt-Jakob disease and has been used as an experimental model.

Adult $\mathrm{C} 3 \mathrm{H}$ mice were infected with ME7 scrapie agent (kindly given to us by $\mathrm{Dr}$ A G Dickinson) and killed after 15 weeks (donors). Their gingival tissues were traumatised lightly with slowly rotating dental burrs, which were then used immediately (without cleaning) to traumatise the gingivae of healthy mice (recipients) under light ether anaesthesia. Controls were treated with burrs used previously on healthy donors. Twentyfour pairs of animals (experimental and control) were thus treated.

After 15 months the recipients were killed, coronal sections of brain and spinal cord cut, and the sections stained by Cajal's gold sublimate impregnation. None of the mice showed astrocytosis characteristic of scrapie infection. However, astrocytosis did develop in mice injected intraperitoneally with 5.0 (but not 0.5 ) $\mathrm{mg}$ infected gingival tissue, indicating the presence in the tissue of scrapie agent at a titre between $10^{2 \cdot 5}$ and $10^{3}$ infective doses per gram wet tissue. The amount of tissue contaminating the burr was found by weighing the burr before and after use to be $50-100$ $\mu \mathrm{g}$; if all of this were transferred the probability of transmission of scrapie can be estimated at approximately 1 in 50 .

If the agent of Creutzfeldt-Jakob disease is similarly distributed the findings suggest that a hazard of transmission of central nervous system (CNS) disorder's of this type by dental procedures exists, although at a low level. If so the prevalence of dental treatment indicates the need for caution in the dental management of patients with CNS disorders of known or suspected slow virus aetiology. ${ }^{1}$ It would seem prudent that dentists, when treating such patients, should follow precautions such as those recommended for carriers of hepatitis $\mathrm{B}, 2: 3$ in particular discarding steel burrs after treatments involving possible gingival trauma.

\section{H ADAMS}

MRC Demyelinating Diseases Unit, Newcastle General Hospital

Department of Oral Physiology,

Dental School

University of Newcastle upon Tyne ' Adams, D H, and Bell, T M, Slow Viruses. Reading,

2 Adams, D, and Zwink, R, British Dental fournal, $1976,141,341$

Nagington, J, and Varley, G W B, British Dental fournal, 1976, 141, 337 .

\section{Cutaneous reactions to labetalol}

SIR,-We have recently investigated a 64year-old man who developed a widespread skin rash while taking labetalol as Trandate; the rash returned on rechallenge with pure labetalol.

Like the patient described by $\mathrm{Dr} R$ W Gange and Professor E Wilson Jones (1 April, p 816), our patient had been taking labetalol $400 \mathrm{mg}$ twice daily for three months when his widespread itchy rash started to appear, and the challenge with pure labetalol resulted in recurrence of the rash also at two weeks. The eruption in our patient was not typical of lichen planus. When seen one month after the onset there was a symmetrical, widespread, scaly erythematous rash. On the extensors of the limbs and back of the hands there was follicular hyperkeratosis and erythema suggestive of pityriasis rubra pilaris. On the lumbar area the scales were heaped up as in psoriasis and on the flanks and sacral area the patches had a cyanotic tinge characteristic of lichen planus. Papules and bullae were absent and the genitalia were not involved.

Biopsy showed patchy basal liquefactive necrosis of the epidermis, intra-epidermal necrotic keratinocytes, and a dermal perivascular lymphocytic infiltrate; these changes are similar to those described by Dr Gange and Professor WilsonJones and are typical of beta-blocker cutaneous eruptions. Direct immunofluorescence showed fibrin deposition at the dermoepidermal junction, with cytoid bodies in a distribution compatible with lichen planus.

Our patient had no ocular or pulmonary abnormalities but had a weakly positive response to tests for antinuclear factor. The drug rechallenge was with "pure" labetalol $400 \mathrm{mg}$ thrice daily supplied by Allen and Hanburys Research Ltd. The repeat cutaneous reaction to this challenge demonstrates that the labetalol is to blame and not the colouring or other constituents of Trandate.

We agree with Dr G M Levene and Dr Gange (25 March, p 784) that early reporting of cutaneous eruptions to new beta-blockers is essential and we hope to report this case in more detail in the near future. We wish to stress that both in our case and in that of $\mathrm{Dr}$ Gange and Professor Wilson-Jones the cutaneous eruption did not occur until the drug had been taken for three months, so that the link with labetalol may not be initially obvious. The interesting feature in our patient is that the eruption and histology were similar to those previously described in association with other heta-blockers-that is, although the histological appearances are compatible with lichen planus the eruption may resemble psoriasis, lichen planus, eczema, and pityriasis rubra pilaris. The clinical picture in our case was, in fact, very similar to that occurring with oxprenolol.

A Y FinLAY

E WADDINGTON

Department of Dermatology,
University Hospital of Wales,
Cardiff

Holt, P J A, and Waddington, E, British Medical
fournal, 1975, 2, 539 .

IR,-We read with interest the report by Dr R W Gange and Professor E Wilson Jones (1 April, $p$ 816) of a patient who developed lichen planus on labetalol.

We have seen a 66 -year-old female patient with essential hypertension who developed a lichenoid eruption after taking labetalol $300 \mathrm{mg}$ thrice daily for 13 months. She first experienced a widespread pruritus and subsequently lesions appeared on her neck and spread to the trunk and limbs, sparing only the face. They were perifollicular, hyperkeratotic, and erythematous and in some areas became confluent. She also complained of a dry mouth and nose, although no lesions were seen on the mucous membranes.

Two biopsy samples showed several areas of hydropic degeneration of the epidermal basal layer; a few Civatte bodies and dyskeratotic cells were present. There was marked follicular hyperkeratosis, a prominent granular layer, and moderate dermal inflammatory infiltrate in relation to the hair follicles and the areas of degeneration. Bullous lesions were not seen. The overall appearances resembled those of lichen planopilaris. Immunofluorescence studies revealed several separate broad areas of linear basement membrane immunofluorescence with antifibrinogen. This band of fluorescence was similar to the findings of Barthelmes and Haustein ${ }^{1}$ in lichen planus, but globular deposits of IgG were not demonstrated.

No relevant autoantibodies were found in the serum. Labetalol treatment was stopped and the patient was given propranolol for hypertension but no specific treatment for her rash. After five weeks the rash cleared, apart from minimal discoloration. Two weeks later she was rechallenged by giving the same dose of labetalol and after a further 10 days the rash recurred with features and distribution similar to the original one. Since stopping the labetalol the second rash has also cleared.

We regard the positive rechallenge in both patients so far reported as evidence of a causal relationship between labetalol and the lichenoid eruptions. The significance of the immunofluorescent findings remains uncertain.

Ruth L Savage M LESNA

J C MUCKLOW C J Stevenson

University Departments of Clinical Pharmacology and Dermatology
and Department of Pathology, Newcastle General Hospital,

Newcastle upon Tyne

Barthelmes, von H, and Haustein, V F, Dermatologische Monatsschrift, 1970, 156, 85.

\section{College of Anaesthetists}

SIR,-It is popular these days to refer to the "Scottish Dimension" when discussing politics, oil, and industry. It seems all the more surprising therefore that none of your correspondents has observed that Scottish anaesthetists have three alternatives to choose from: (1) no change in the present arrangement ; (2) an independent College of Anaesthetists in London; and (3) an independent College of Anaesthetists in Scotland.

A meeting to discuss the matter will be held in Edinburgh on 11 April. In a profession that 